\title{
Avaliação da Atividade Cicatricial do Aloe vera em Feridas em Dorso de Ratos*
}

\author{
Cicatricial Activity Evaluation of Aloe vera on Wounds in Rats
}

\section{Cicatricial Actividad Evaluación de Aloe vera en Heridas en Ratas}

\author{
Patrícia Lima Mercês', Lilhian Alves de Araújo ${ }^{1}$, Ana Carolina Vicente Araújo', \\ Maísa Helena de Abreu Silva Santos ${ }^{1}$, Susy Ricardo Lemes ${ }^{1}$, Paulo Roberto de Melo-Reis ${ }^{1}$
}

\begin{abstract}
RESUMO
A Aloe vera, popularmente conhecida como babosa, é uma das plantas mais utilizadas no tratamento de feridas, visto que inúmeras pesquisas relatam suas propriedades cicatrizantes e anti-inflamatórias. O objetivo do estudo foi avaliar a influência da Aloe vera na atividade cicatricial de feridas induzidas em dorso de ratos. Foram utilizados 15 ratos saudáveis da espécie Rattus norvegicus albinus. Por intermédio da criação de uma lesão no dorso de cada rato utilizando um molde do tamanho retangular 2,0 × 3,0 cm, foi aplicado o gel de Aloe vera, solução teste, além dos controles positivo e negativo. Os resultados na avaliação macroscópica demonstraram que 100\% dos ratos tratados com o gel de Aloe vera apresentaram um fechamento completo das lesões no $21^{\circ}$ dia do experimento. O grupo controle positivo obteve $40 \%$ das amostras com fechamento completo. A análise estatística demonstrou, no entanto, que não houve diferença significativa entre o grupo teste e o grupo controle positivo $(p>0,05)$, porém houve diferenças $(p<0,05)$ entre o grupo teste e o controle negativo. Por meio dos resultados obtidos, concluiu-se que o gel de Aloe vera apresenta potencial aplicabilidade farmacêutica para o tratamento de feridas, podendo apresentar componentes isolados pró-angiogênicos.
\end{abstract}

DESCRITORES: Babosa. Cicatrização. Fitoterapia. Estomaterapia.

\begin{abstract}
The Aloe vera, popularly known as aloe, is one of the plants most commonly used in the treatment of wounds, since numerous studies reporting their anti-inflammatory and cicatrizing properties. The aim of the study was to evaluate the influence of Aloe vera in the healing activity of wounds induced in rats. Fifteen healthy rats Rattus norvegicus albinus were used. By creating a lesion on the back of each rat using a rectangular size of $2.0 \times 3.0 \mathrm{~cm}$ mold, Aloe vera gel has been applied, the test solution, in addition to positive and negative controls. The results in macroscopic evaluation showed that 100\% of the mice treated with Aloe vera gel showed a complete closing of the injury on day 21 of the experiment. The positive control group had $40 \%$ of the samples with complete closure. Statistical analysis showed, however, that there was no significant difference between the test group and the control group ( $p>0.05)$, however there were differences $(p<0.05)$ between the test group and the negative control. From the results obtained, it was concluded that the Aloe vera gel has potential pharmaceutical applicability for the treatment of wounds, and may have a single component pro-angiogenic.
\end{abstract}

DESCRIPTORS: Aloe. Wound healing. Phytotherapy. Stomatherapy.

Endereço para correspondência: Rua 232,128, $3^{\circ}$ Andar, Sala 5 - CEP: 74605-010 - Goiânia (GO), Brasil - E-mail: patricialimamerces@gmail.com *Artigo retirado de Dissertação de Mestrado em Ciências Ambientais e Saúde com título "Avaliação das Atividades Angiogênica e Cicatricial do Extrato de Aloe vera (Aloe barbadensis)", defendida por Patricia Lima Mercês em maio de 2015 na Pontifícia Universidade Católica de Goiás (PUC-GO).

'Pontifícia Universidade Católica de Goiás (PUC-GO) - Goiânia (GO), Brasil.

Artigo recebido em: 07/03/2016 - Aceito para publicação em: 21/06/2016 


\section{RESUMEN}

La Aloe vera, popularmente conocido como aloe, es una de las plantas más utilizadas en el tratamiento de heridas, ya que numerosos estudios relatan sus propiedades cicatrizantes y antiinflamatorias. El objetivo del estudio fue evaluar la influencia de Aloe vera en la actividad cicatricial de heridas inducidas en dorso de ratones. Fueron utilizados 15 ratones sanos de la especie Rattus norvegicus albinus. Mediante la creación de una lesión en en el dorso de cada ratón utilizando un molde de tamaño rectangular de 2,0 × 3,0 cm, fue aplicado el gel de Aloe vera, solución test, además de los controles positivo y negativo. Los resultados en la evaluación macroscópica demostraron que 100\% de los ratones tratados con el gel de Aloe vera presentaron un cierre completo de las lesiones en el día 21 del experimento. El grupo de control positivo obtuvo 40\% de las muestras con cierre completo. El análisis estadístico demostró, mientras tanto, que no hubo diferencia significativa entre el grupo test y el grupo control ( $p>0,05)$, sin embargo hubo diferencias $(p<0,05)$ entre el grupo test y el control negativo. De los resultados obtenidos se concluye que el gel de Aloe vera tiene potencial de aplicabilidad farmacéutica para el tratamiento de heridas, pudiendo presentar componentes aislados pro-angiogénicos.

DESCRIPTORES: Aloe. Cicatrización. Fitoterapia. Estomaterapia.

\section{INTRODUÇÃO}

As plantas são utilizadas pelo homem, desde o início de sua história, para o tratamento de diversas doenças, e o uso de substâncias de origem vegetal ou animal para fins medicinais continua sendo um hábito frequente nas culturas dos mais diferentes povos do planeta ${ }^{1,2}$. Inúmeras pesquisas relatam que, apesar do desenvolvimento de fármacos sintéticos, as plantas medicinais continuam sendo uma alternativa no tratamento de diversas doenças em várias regiões do mundo ${ }^{3}$.

A Organização Mundial de Saúde estima que cerca de $80 \%$ da população de países em desenvolvimento faça uso de plantas para o tratamento de alguma doença ${ }^{4}$. Esse fato pode ser explicado tanto por questões culturais quanto pelo acesso limitado aos serviços de saúde e, nos países desenvolvidos, pelo modismo de consumir produtos naturais ${ }^{5}$.

No Brasil, 82\% da população utiliza produtos à base de plantas medicinais, muitos desses com pouca ou nenhuma comprovação científica quanto às suas propriedades farmacológicas e à sua eficácia. $\mathrm{O}$ uso desses produtos é difundido principalmente pelo conhecimento popular transmitido de geração a geração ${ }^{6}$. Em contrapartida, as últimas décadas vivenciaram importantes avanços com a formulação e implementação de políticas públicas visando à utilização das plantas medicinais e derivados e sua inserção na rede de saúde. Porém, diante do potencial observado na flora brasileira, por sua biodiversidade, é imprescindível a ampliação do investimento em pesquisas, para que os usuários desses produtos tenham acesso a eles com qualidade, eficácia e segurança ${ }^{7,6}$.
Inúmeros vegetais apresentam um grande potencial no tratamento e na cicatrização de feridas, sendo utilizados em vários países para tratar lesões de etiologias distintas $^{8}$. Atualmente, estudos experimentais utilizando plantas medicinais e outros compostos que atuam na cicatrização estão sendo desenvolvidos, e já existem no mercado produtos de origem vegetal para fins medicinais 9 .

Uma importante planta medicinal utilizada na cultura popular para o tratamento de vários tipos de lesões cutâneas é a Aloe barbadensis, conhecida popularmente no Brasil por babosa. Essa planta de origem africana pertence à família das Liliáceas, assemelha-se a um cacto e cresce em climas tropicais. Há mais de 300 espécies de Aloe catalogadas, porém, como a maioria é venenosa, somente 4 espécies são seguras quanto ao uso em seres humanos, merecendo destaque as espécies Aloe arborensis e Aloe barbadensis, sendo esta última a de maior concentração em nutrientes em seu gel (comumente denominada de Aloe vera), fato que caracteriza seu amplo uso na medicina curativa ${ }^{10-12}$.

A ação terapêutica da Aloe vera é citada em inúmeros trabalhos experimentais e tem sido utilizada na medicina tradicional na cura de diversos males, dentre eles lesões da pele, como queimaduras, danos por irradiação, úlceras venosas e isquêmicas. A Aloe vera apresenta também ação cicatrizante, anti-inflamatória, protetora da pele, devido, fundamentalmente, ao seu poder emoliente e suavizante, além de conter as vitaminas $\mathrm{C}, \mathrm{E}$ e do complexo $\mathrm{B}$ e ácido fólico, aminoácidos essenciais e polissacarídeos que estimulam o crescimento dos tecidos e a regeneração celular ${ }^{13-15}$.

Vários relatos afirmam que Aloe vera tem influência benéfica na cicatrização de feridas em ratos normais 
e diabéticos, por exercer efeito estimulante imunológico, ativando os macrófagos ${ }^{16}$. O processo de cicatrização ou reparação pode ser dividido em três estágios distintos, mas sobrepostos. $\mathrm{Na}$ fase inflamatória, que pode ser intensa ou duradora, dependendo do grau de lesão tecidual, ocorre o recrutamento e a proliferação dos fibroblastos. $\mathrm{O}$ segundo estágio, chamado de fase proliferativa, é caracterizado pela deposição do colágeno, da angiogênese, para formar o tecido cicatricial. No terceiro e último estágio, o colágeno extracelular é remodelado e disposto em feixes paralelos. A derme regenerada, entretanto, difere da derme saudável, uma vez que certos componentes da pele, depois de lesados, não podem ser recuperados, como os folículos pilosos e as glândulas sudoríparas ${ }^{16,17}$.

O uso tópico da Aloe vera tem o papel de fornecer mais oxigênio, aumentando a vascularização e a quantidade de colágeno para que o processo de cicatrização aconteça. Com seu uso, o tecido é desinflamado, ocorrendo a multiplicação das células epiteliais ${ }^{10,18}$. Diante do exposto, este estudo buscou avaliar os efeitos da Aloe vera (Aloe barbadensis) em relação à sua atividade cicatricial, mediante a realização de experimentos in vivo, utilizando como modelo experimenta lesões induzidas em dorso de ratos.

\section{METODOLOGIA}

O presente estudo foi realizado no Laboratório de Estudos Experimentais Biotecnológicos da Pontifícia Universidade Católica de Goiás (PUC), em Goiânia, após a aprovação pela Comissão de Ética de Uso de Animais (CEUA) da instituição, sob o Protocolo $n^{\circ}$ 0007-1. Os animais foram mantidos do início ao fim da pesquisa para coleta de dados e avaliação clínica, sendo obedecidos os princípios éticos em experimentação animal preconizados pela CEUA.

\section{Obtenção do gel de Aloe vera (Aloe barbadensis)}

O extrato clicólico de Aloe vera foi adquirido da empresa farmacêutica de manipulação Vitória Régia, CNPJ no 04.270.183/0002-05, localizada em Araguaína, Tocantins, manipulado pelo farmacêutico Lucas Corrêa Mendes (CRF-TO 1512). Foi utilizado Aloe vera a $10 \%$ em gel, fabricado em 28 de abril de 2014 e com vencimento em 28 de setembro de 2014 sob o Registro no 153131.

\section{Composição}

O Aloe vera em gel a 10\% foi composto por: extrato glicólico de Aloe vera - $10 \mathrm{~mL}$ e Gel hidro-alcóolico qsp - $100 \mathrm{~g}$. O extrato glicólico de Aloe vera foi composto por: mucilagem de Aloe vera $-500 \mathrm{~g}$, álcool de cereais a $80^{\circ} \mathrm{GL}-950 \mathrm{~mL}$, e propilenoglicol $-50 \mathrm{~mL}$.

\section{Amostragem experimental}

Para realizar a pesquisa foram utilizados 15 ratos, saudáveis, da espécie Rattus norvegicus albinus, Rodentia mammalia, oriundos do Biotério da PUC-GO, apresentando peso corpóreo entre 200 e 300 g e faixa etária entre 2 e 3 meses no dia do experimento. Esses animais foram ambientados e climatizados por 10 dias, para adaptação, recebendo água e ração balanceada ad libitum. Foram utilizados no estudo os animais que apresentaram condições físico-clínicas apropriadas para realização da pesquisa $(n=15)$, seguindo as normas da CEUA.

Os animais foram alojados em gaiolas individuais de polipropileno, forradas com maravalha, conforme padrões internacionais. A maravalha foi trocada a cada três dias. O laboratório para alojamento dos animais apresentava-se arejado e com temperatura média de $21^{\circ} \mathrm{C}$, com sistema de ventilação e ciclo de claro-escuro (claridade 07h00-19h00, escuro 19h00-07h00). A alimentação (água e ração) foi suspensa 8 horas do antes do experimento, sendo retomada 4 horas após a recuperação dos sentidos da indução anestésica.

\section{Anestesia, tricotomia e excisão da pele}

Os animais foram anestesiados com quetamina $(87 \mathrm{mg} / \mathrm{kg})$ e xilazina $(13 \mathrm{mg} / \mathrm{kg})$ por via intraperitoneal. Após indução anestésica, os ratos foram posicionados em decúbito ventral, colocados em prancha de acrílico e submetidos à tricotomia da região dorsal com o auxílio de lâmina específica para realização do procedimento. A excisão foi realizada utilizando um molde do tamanho retangular 2,0 $\mathrm{x}$ 3,0 $\mathrm{cm}$ para retirada do fragmento constituído de pele e tecido subcutâneo. Todo o procedimento cirúrgico foi realizado utilizando técnica séptica.

Em seguida, os animais foram identificados de 1 a 15, com tintura de pincel permanente, nas orelhas e na cauda. As gaiolas nas quais os animais foram alojados também receberam a mesma identificação. 
A escolha do dorso do rato para a excisão da pele teve como objetivo impedir que o próprio animal conseguisse atingir a lesão, além de ser um modelo amplamente utilizado nos trabalhos de cicatrização. O processo cicatricial foi avaliado por observação macroscópica da lesão e por registro fotográfico nos dias $0,7,14$ e 21 .

\section{Grupos experimentais e tratamento tópico}

Os animais foram distribuídos aleatoriamente em grupos conforme o agente tópico estudado, sendo:

- Grupo R - animais com numeração de 1 a 5 - controle positivo;

- Grupo AV - animais com numeração de 6 a 10 - solução teste Aloe vera a 10\%;

- Grupo SF - animais com numeração de 11 a 15 - controle negativo.

Em todos os grupos (R, AV e SF) foram realizados curativos diários com a aplicação do produto correspondente até a cicatrização total da ferida. Após a excisão da pele e a identificação do animal, foi realizado o primeiro registro fotográfico e aplicado o agente tópico específico de cada grupo. Em seguida, ocorreu novamente o registro fotográfico apresentando o produto aplicado na lesão. Não foi utilizada nenhuma cobertura secundária nas lesões dos indivíduos de cada grupo (Figura 1).

\section{Descrição da realização dos curativos}

Os curativos foram feitos diariamente no mesmo horário, precedidos de atividade antisséptica na bancada e prancha de acrílico utilizada no momento do curativo. Foi utilizado frasco de $250 \mathrm{~mL}$ de solução salina $0,9 \%$, previamente aquecida em uma estufa a $37^{\circ} \mathrm{C}$ perfurada com agulha $40 \times 12 \mathrm{~mm}$.

Os ratos foram dispostos um por vez na prancha de acrílico e tiveram o local da lesão irrigado com solução salina a 0,9\%, para remoção de sujidades e restos de tecido dérmico. Após a remoção do excesso da solução da área peri-ferida com gazes, foi colocado $1 \mathrm{~mL}$ da terapia tópica na lesão de acordo com cada grupo. Posteriormente, aspirou-se $1 \mathrm{~mL}$ do tópico para deposição na espátula, a fim de realizar a aplicação nos ratos. A espátula foi descartada após cada aplicação e foi utilizada uma seringa para cada grupo do experimento.

No momento da realização dos curativos fez-se a avaliação macroscópica das lesões quanto ao tamanho e à presença de esfacelo ou crosta (necrose) e de exsudato (purulento ou sanguinolento).

\section{Avaliação da evolução da cicatrização}

Por meio de câmara digital Sony Cyber-shot (8.1 megapi$x e l s$ ), foram obtidas as imagens das lesões induzidas na pele, em tamanho 640 X 480 pixels e formato de RGB 24 bites, sem aproximação de zoom à distância de $24 \mathrm{~cm}$.

As avaliações e os curativos foram realizados diariamente. A área correspondente à ferida da pele foi medida pela utilização do programa IMAGEJ. Os dados obtidos foram arquivados em planilha de cálculo do programa Excel, Microsoft ${ }^{\circledR}$, para posterior quantificação das áreas e respectivas comparações.

\section{Análise estatística}

A avaliação da cicatrização nos 3 grupos experimentais foi realizada nos dias 7,14 e 21. Foram comparadas as áreas das
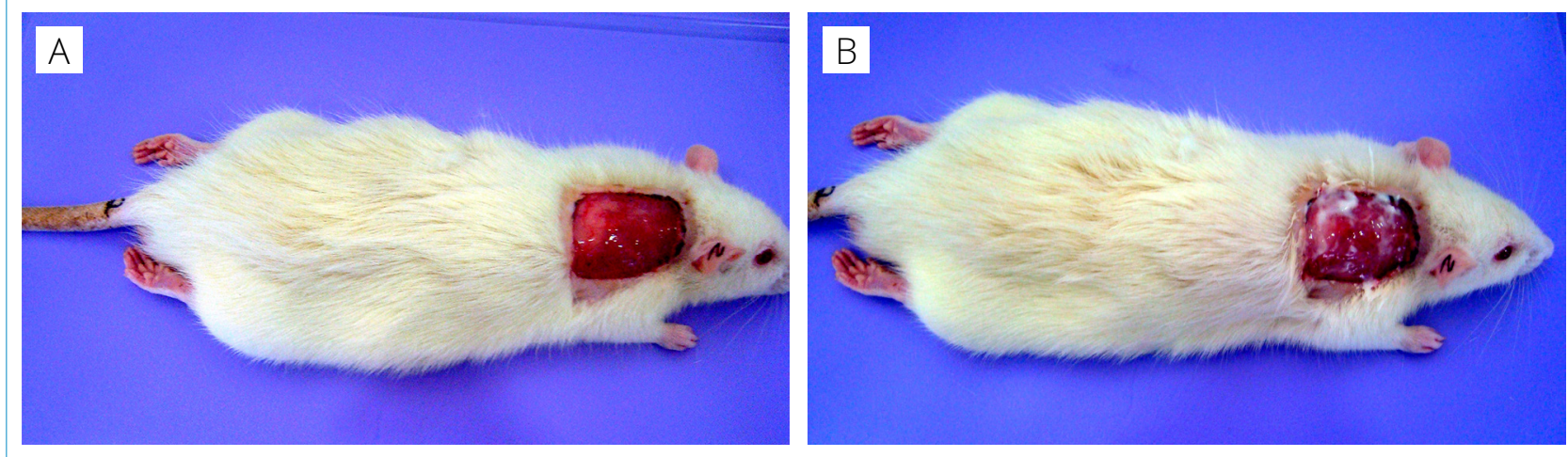

Figura 1. Grupo R: sem o produto (A) e com o produto (B). 
lesões pelo teste $\mathrm{F}$ (ANOVA) e, posteriormente, foi feita a comparação entre as médias das áreas lesadas pelo teste de Tukey. $\mathrm{O}$ valor de $\mathrm{p}$ foi considerado significativo quando menor que 0,05 .

\section{RESULTADOS}

Após a realização da excisão da pele de todos os animais, eles se recuperam satisfatoriamente da anestesia. Houve apenas 1 óbito $24 \mathrm{~h}$ após o início do experimento, e o animal foi imediatamente substituído. Nos demais dias do experimento não houve nenhuma complicação. As avaliações e os curativos foram realizados diariamente (Quadro 1).
Os Grupos R e AV apresentaram maior velocidade no fechamento das feridas em relação ao Grupo SF. A área da ferida diminuiu gradativamente da periferia para o centro (Figura 2). No dia zero, as médias das áreas excisadas foram comparadas entre si, não apresentando diferenças estatísticas significantes $(p>0,05)$. Na observação das regiões lesionadas no sétimo dia de evolução, também não houve diferenças estatísticas significantes entre os grupos ( $p>0,05)$. Progredindo a avaliação da cicatrização nos dias 14 e 21, os Grupos R e AV não apresentaram diferenças significativas, respectivamente. Entretanto, houve diferença no Grupo SF, quando comparado aos Grupos R e AV, nos $14^{\circ}$ e $21^{\circ}$ dias de evolução $(p<0,05)$ (Figura 2).

Quadro 1. Avaliação macroscópica das lesões no dorso dos ratos.

\begin{tabular}{|c|c|c|c|c|c|c|c|c|}
\hline Dias & & Crosta & Esfacelo & $\begin{array}{l}\text { Tecido de } \\
\text { granulação }\end{array}$ & $\begin{array}{c}\text { Exsudato } \\
\text { sanguinolento }\end{array}$ & $\begin{array}{c}\text { Tecido de } \\
\text { epitelização }\end{array}$ & $\begin{array}{c}\text { Fechamento } \\
\text { parcial }\end{array}$ & $\begin{array}{c}\text { Fechamento } \\
\text { total }\end{array}$ \\
\hline \multirow{3}{*}{$1-2$} & Grupo R & -- & - & -- & 5 & ---- & -- & -- \\
\hline & Grupo AV & -- & - & -- & 5 & ---- & -- & -- \\
\hline & Grupo SF & -- & - & -- & 5 & ---- & -- & -- \\
\hline \multirow{3}{*}{3} & Grupo R & 1 & - & 2 & 2 & ---- & & \\
\hline & Grupo AV & ---- & - & 5 & -- & ---- & ---- & ---- \\
\hline & Grupo SF & ---- & - & 5 & --- & ---- & ---- & ---- \\
\hline \multirow{3}{*}{$4-6$} & Grupo R & 1 & 3 & 1 & ---- & ---- & ---- & ---- \\
\hline & Grupo AV & 1 & 3 & 1 & ---- & ---- & ---- & ---- \\
\hline & Grupo SF & 5 & - & ------ & ---- & ---- & ---- & ---- \\
\hline \multirow{3}{*}{ 7-9 } & Grupo R & --- & 5 & ----- & --- & ---- & ---- & ---- \\
\hline & Grupo AV & ---- & 5 & ------ & ---- & ---- & ---- & ---- \\
\hline & Grupo SF & 5 & - & ----- & ---- & ---- & ---- & ---- \\
\hline \multirow{3}{*}{$10-13$} & Grupo R & ---- & - & 5 & ----- & 5 & ---- & ---- \\
\hline & Grupo AV & ---- & - & 5 & ----- & 5 & & ---- \\
\hline & Grupo SF & 4 & - & 1 & ----- & 5 & 5 & ---- \\
\hline \multirow{3}{*}{ 14-20 } & Grupo R & --- & - & --- & --- & 5 & 5 & --- \\
\hline & Grupo AV & ---- & - & ---- & ---- & 5 & 5 & ---- \\
\hline & Grupo SF & ---- & - & ----- & ----- & 5 & 5 & ---- \\
\hline \multirow{3}{*}{21} & Grupo R & ---- & - & ---- & ---- & ---- & 3 & 2 s/ retração \\
\hline & Grupo AV & ---- & - & ---- & ---- & ---- & ---- & 5 c/ retração \\
\hline & Grupo SF & ---- & - & ---- & ---- & ---- & 5 & ---- \\
\hline
\end{tabular}




\section{DISCUSSÃO}

Os resultados obtidos demonstraram que a Aloe vera, em comparação ao Regederm ${ }^{\circledR}$, não apresentou uma diferença estatística pelo teste de Tukey, demonstrando, assim, que a atividade cicatricial da Aloe vera é igual à do Regederm ${ }^{\circledR}$, que já possui comprovação científica na cicatrização de feridas ${ }^{18}$.

Durante 21 dias foi observado o processo de cicatrização, com registros fotográficos nos dias $0,7,14$ e 21; os curativos foram feitos diariamente, no mesmo horário, com técnica asséptica. A avaliação macroscópica permitiu o acompanhamento de todo o processo de cicatrização da lesão, em que foram avaliadas a presença de distúrbios hemorrágicos e a formação de crostas e de exsudato (Quadro 1).

Durante o experimento nenhum rato apresentou hemorragia e exsudato, porém houve a formação de crostas entre o terceiro e o sétimo dia, assim como a presença de uma pequena camada de fibrina entre o sétimo e o décimo dia. Observou-se ainda a presença de tecido de granulação em todos os indivíduos desde o terceiro dia.

A crosta formada nos ratos de todos os grupos foi retirada no sétimo dia do experimento por meio de desbridamento mecânico utilizando técnica de cover, pois a permanência das cascas retardaria o processo de cicatrização. Após a realização do desbridamento, apenas os ratos do Grupo SF voltaram a apresentar crostas, que foram retiradas decorrer dos dias no momento da realização dos curativos.

A diminuição das lesões pôde ser observada no grupo com Aloe vera a partir do sétimo dia, iniciando-se das margens da lesão para o leito. No 14 dia, 100\% ratos do Grupo AV já apresentavam cicatrização quase total da lesão, enquanto os Grupos R e SF ainda apresentavam cicatrização parcial. Desse modo, verificou-se que o tempo de cicatrização do Grupo AV foi menor em relação aos Grupos R e SF. No 21 dia do experimento, o fechado total das lesões foi verificado

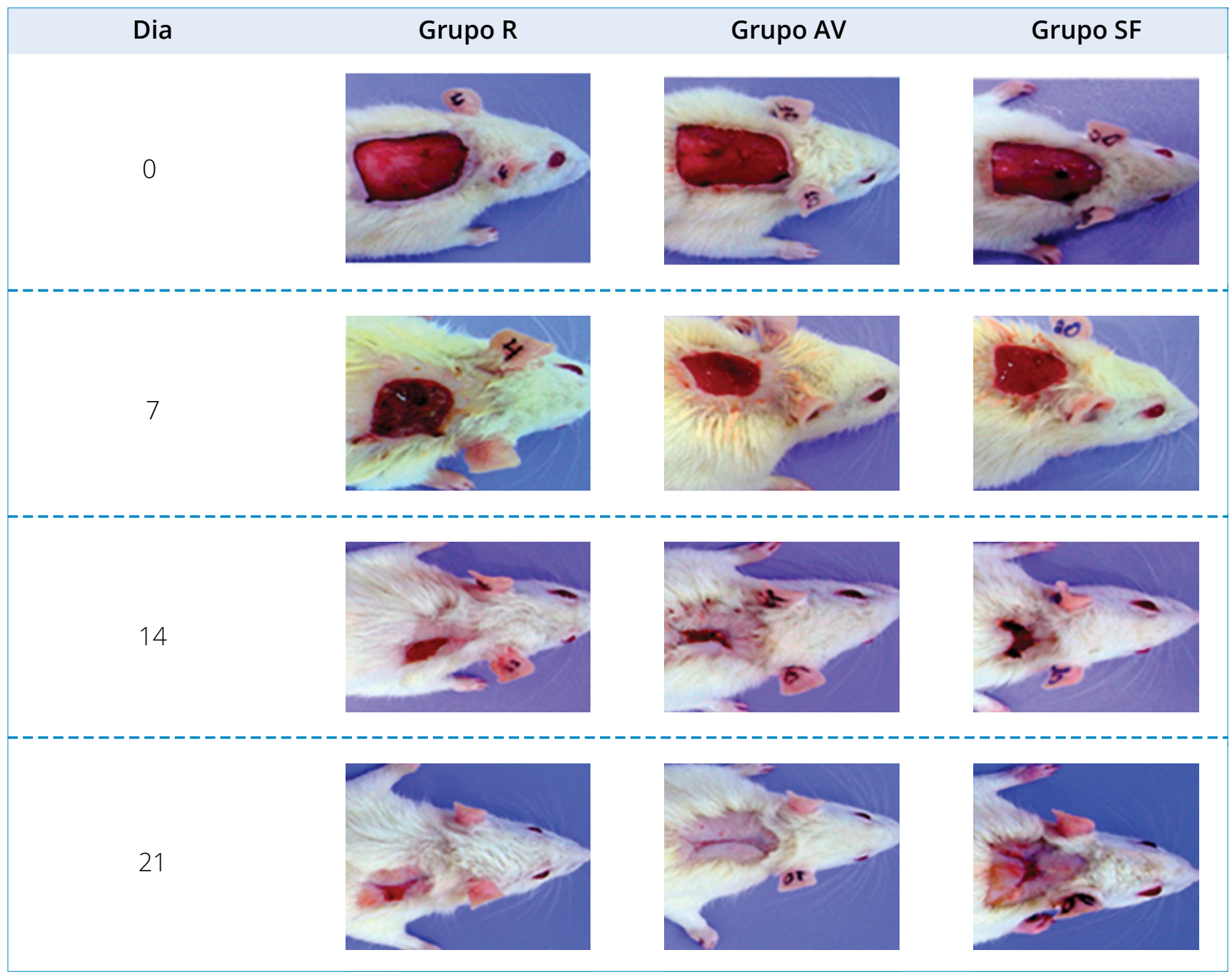

Figura 2. Demonstração da velocidade de cicatrização da cada grupo. 
em 100\% dos ratos do Grupo AV, em 40\% no Grupo R e em apenas $20 \%$ no Grupo SF.

Diferentes estudos relatam que a Aloe vera possui atividade cicatricial em feridas, especialmente as cutâneas. Esse vegetal tem capacidade de manter a ferida úmida, facilitando a migração celular epitelial, permitindo que a maturação do colágeno ocorra mais rapidamente, além de reduzir o tempo de inflamação da lesão ${ }^{19,20}$. Além disso, esse vegetal contém uma glicoproteína que promove a atividade celular, aumentando o fornecimento de sangue e, consequentemente, a oxigenação para lesão ${ }^{21}$.

É importante ressaltar que esse vegetal apresenta importantes constituintes, como as aloínas A, B2 e C, cromonas, açúcares como glucose, manose e celulose, enzimas como oxidase, amilase e catalase, além das vitaminas B1, B2, B6, C, E e ácido fólico, e minerais como o cálcio, sódio, magnésio, zinco, cobre e cromo ${ }^{22}$. As folhas da Aloe vera dispõem-se sob a forma de mucilagem (gel), a qual é constituída por glicoproteínas e polissacarídeos que impedem o processo inflamatório e a dor, aceleraram a cicatrização e estimulam o crescimento da pele. $\mathrm{O}$ gel dessa planta pode ser usado para o tratamento de feridas internas e externas ${ }^{23,24}$.

A propriedade cicatricial da Aloe vera está relacionada a um importante composto denominado glucomanano, o qual é enriquecido com polissacarídeos como a manose. Estudos demonstram que essa substância, além de estimular a liberação do fator de crescimento vascular endotelial (VEGF), interfere na ação do fator de crescimento fibroblástico, estimulando a atividade e a proliferação de células fibroblásticas e, por sua vez, contribuindo para a produção de colágeno e secreções. A mucilagem da Aloe vera também aumenta o número de ligações transversais entre as proteínas de colágeno, criando uma mudança na estrutura de colágeno, a qual resulta no aceleramento do processo cicatricial ${ }^{25,26}$.
Outras pesquisas apontam que a mucilagem desse vegetal acelera a cicatrização de feridas presentes em ratos com diabetes devido ao seu potencial em elevar a taxa de expressão do gene codificador de VEGF e fator de crescimento transformador (TGF) $\beta$-1 na região lesada. Desse modo, o TGF- $\beta 1$ estimula a produção de fibroblastos para a reconstrução da matriz extracelular no local da ferida. Assim, o emprego do gel de Aloe vera tem sido destinado à cicatrização de feridas em menor tempo possível, com redução de dor e cicatrizes ${ }^{27,28}$.

A aceleração da cicatrização utilizando a Aloe vera em feridas no dorso de ratos também já foi detectada em estu$\operatorname{dos}^{29}$. Além disso, experimentos de queimaduras induzidas no dorso de ratos demonstraram que a Aloe vera reduziu o tempo de cicatrização das lesões, quando comparada com o agente cicatricial sulfadiazina de prata ${ }^{30,31}$.

Um estudo realizado utilizando Aloe vera a $3 \% \mathrm{em}$ pacientes com úlceras por pressão verificou que, apesar de não ter ocorrido uma diminuição das lesões, o uso contínuo do gel proporcionou o amolecimento do tecido necrótico, possibilitando sua excisão em um curto período de tempo. Esse evento é importante no cuidado de feridas crônicas, já que a presença de tecido necrótico retarda o processo cicatricial e propicia a infecção ${ }^{32}$.

\section{CONCLUSÃO}

A partir dos métodos e das condições empregadas neste estudo, os resultados permitiram concluir que o extrato de Aloe vera apresentou uma velocidade de cicatrização semelhante ao controle positivo, além de demonstrar, na avaliação estética cicatricial, pequenas retrações sem elevação. Desse modo, infere-se que seu extrato e seus possíveis componentes pró-angiogênicos isolados apresentam potencial aplicabilidade farmacêutica no tratamento de feridas.

\section{REFERÊNCIAS}

1. Carneiro FM, Silva MJPD, Borges LL, Albernaz LC, Costa JDP. Tendências dos estudos com plantas medicinais no Brasil. Rev Sapiência. 2014;3(2):44-75.

2. Nicoletti MA, Carvalho KC, Oliveira JRMA, Bertasso CC, Caporossi PY, Tavares APL. Uso popular de medicamentos contendo drogas de origem vegetal e/ou plantas medicinais: principais interações decorrentes. Rev Saúde. 2010;4(1):25-39.
3. Badke MR, Budó MDLD, Alvim NAT, Zanetti GD, Heisler EV. Saberes e práticas populares de cuidado em saúde com o uso de plantas medicinais. Texto Contexto - Enferm. 2012;21(2):363.

4. WHO - World Health Organization. Regional office for the Western Pacific. Research guidelines for evaluating the safety and efficacy of herbal medicines. Manila: WHO; 1993. $86 p$. 
5. Brasil. Práticas Integrativas e Complementares: plantas medicinais e fitoterapia na Atenção Básica/Ministério da Saúde. Secretaria de Atenção à Saúde. Departamento de Atenção Básica. Brasília: Ministério da Saúde; 2012. (Cadernos de Atenção Básica; n. 31, 156p).

6. Rodrigues AG, De Simoni C. Plantas medicinais no contexto de políticas públicas. Informe Agropecuário. 2010;31(255):7-12.

7. Brasil. Política Nacional de Plantas Medicinais e Fitoterápicos. Secretaria de Ciência, Tecnologia e Insumos Estratégicos, Departamento de Assistência Farmacêutica. Brasília: Ministério da Saúde; 2006. 60p.

8. Thakur RJN, Pathak RE, Sandhu SS. Practices in Wound Healing Studies of Plants. Evidence-Based Complementary and Alternative Medicine. 2011;2011(Article ID 438056):17. doi:10.1155/2011/438056. 2011.

9. Vargas NRC, Ceolin T, Souza ADZD, Mendieta MDC, Ceolin S, Heck RM. Plantas medicinais utilizadas na cicatrização de feridas por agricultores da região sul do RS. Rev Pesqui Cuid Fundam. 2014;6(2):550-60.

10. Dat AD, Poon F, Pham KBT, Doust J. Aloe vera for treating acute and chronic wounds. Cochrane Database Syst Rev. 2012;(2):CD00876.

11. Bomtempo M. O livro definitivo do Aloe vera, a planta milenar da saúde. Brasília: Thesaurus; 2012. 104p.

12. Bhat G, Kudva P, Dodwad V. Aloe vera: nature's soothing healer to periodontal disease. J Indian Soc Periodontol. 2011;15(3):205-9.

13. Oliveira SHS, Soares MJGO, Rocha RS. Uso de cobertura com colágeno e Aloe Vera no tratamento de ferida isquêmica: estudo de caso. Rev Esc Enferm USP. 2010;44(2):346-51.

14. Domansky RC, Borges EL. Manual para Prevenção de Lesões de Pele: Recomendações Baseadas em Evidências. Rio de Janeiro: Rubio; 2012. 270p.

15. Gogia PP. Feridas: tratamento e cicatrização. Rio de Janeiro: Revinter Ltda.; 2003.

16. Khan AW, Kotta S, Ansari SH, Sharma RK, Kumar A, Ali J. Formulation development, optimization and evaluation of aloe vera gel for wound healing. Pharmacogn Mag. 2013;9(Suppl 1):S6-S10.

17. King TC. Patologia; Rio de Janeiro: Elservier; 2007. 436p.

18. Ferreira $M$, Mendonça RJ, Coutinho-Netto J, Mulato $M$. Angiogenic properties of natural rubber latex biomembranes and the serum fraction of Hevea brasiliensis. Braz J Phys. 2009;39(3):564-69.
19. De Paula Ramos A, Pimentel LC. Ação da Babosa no reparo tecidual e cicatrização/Effectiveness of Aloe vera on the tissue repair and healing process. Braz J Health. 2011;1:40-8.

20. Wynn RL. Aloe vera gel: update for dentistry. Gen Dent. 2005;53(1):6-9.

21. Gupta VK, Seema M. Pharmacological Attribute of Aloe Vera: Revalidation through Experimental and Clinical Studies. Ayu. 2012;33(2):193-6.

22. Surjushe A, Vasani R, Saple D. Aloe vera: a short review. Indian J Dermatol. 2008;53(4):163-6.

23. Moreira LRS, Filho EXF. An overview of mannan structure and mannan-degrading enzyme systems. Appl Microbiol Biotechnol. 2008;79(2):165-78.

24. Eshun K, He Q. Aloe vera: a valuable ingredient for the food, pharmaceutical and cosmetic industries - a review. Crit Rev Food Sci Nutr. 2004;44(2):91-6.

25. Boudreau MD, Beland FA. An evaluation of the biological and toxicological properties of Aloe barbadensis (Miller), Aloe vera. J Environ Sci Health C Environ Carcinog Ecotoxicol Rev. 2006;24(1):103-54

26. Majewska I, Gendaszewska-Darmach E. Proangiogenic activity of plant extracts in accelerating wound healing-a new face of old phytomedicines. Acta Biochim Pol. 2011;58(4):449-60.

27. Freitas VS, Rodrigues RAF, Gaspi FOG. Pharmacological activities of Aloe vera (L.) Burm. f. Rev Bras Plantas Med. 2014;16(2):299-307.

28. Atiba A, Ueno $H$, Uzuka Y. The effect of aloe vera oral administration on cutaneous wound healing in type 2 diabetic rats. J Vet Med Sci. 2011;73(5):583-9.

29. Hashemi SA, Madani SA, Abediankenari S. The review on properties of Aloe vera in healing of cutaneous wounds. Biomed Res Int. 2015;2015:714216.

30. Faleiro CC, Elias STH, Cavalcanti LC, Cavalcanti ASS. O extrato das folhas de babosa, Aloe vera na cicatrização de feridas experimentais em pele de ratos, num ensaio controlado por placebo [Internet]. [cited 2015 Nov 06]. Natureza on line. 2009;7(2):56-60. Disponível em: http://www.naturezaonline. com.br/natureza/conteudo/pdf/01_faleiroetal_5660.pdf.

31. Akhoondinasab MR, Akhoondinasab M, Saberi M. Comparison of Healing Effect of Aloe Vera Extract and Silver Sulfadiazine in Burn Injuries in Experimental Rat Model. World J Plast Surg. 2014;3(1):29-34.

32. Simão CMF, Poletti NAA, Rodrigues CDS, Pereira APS. O uso do Aloe Vera em úlceras por pressão. Rev Estima. 2005;3(4):18-24. 